\title{
DEFENDING RADICALISM AND ISLAMIC-TRANSNATIONAL MOVEMENT; RENEWAL APPROACHES FROM STRUCTURAL TO CULTURAL DIMENSION
}

\author{
Ana Aniati \\ Institut Agama Islam Ibrahimy Genteng Banyuwangi, Indonesia \\ E-mail: anaaniaty@yahoo.com
}

\begin{abstract}
This article will describe complete approaches to understand what trans-nationalism is, how to anticipate its negative effects trough Islamic authentic feature which is lived in and attached by Indonesian-Moslems societies, and strategy to build a tolerance and multicultural society beyond rising Islamism and nationalism contestation, at least in few months ago. To construct this complex idea, this article will be formulated using sociological and anthropological design-approaches in every sub-theme. Yet this article was constructed using some researches reports which were have done. In the end, this article will conclude that; first trans-nationalism was not a dangerous theme, if Indonesian people belonging to their identities as attached feature. Second, Indonesian people had a strong institution (Pesantren) to build tolerance and multicultural Moslems societies. Third, Moslems scholars, such as Kyais and Moslem Intellectual ought to usually preach what Indonesia is based on cultural and nationalism values. The last, we have to recognize that uncertain political interest will arose all of Indonesia moderate world view.
\end{abstract}

Keywords: Trans-nationalism, Pesantren, Tolerance and Multicultural Societies

\section{Pendahuluan}

Kegelisahan utama tema ini berasal dari kekhawatiran banyak orang akan menguatnya kembali konflik sikap islamisme radikal dan pupusnya identitas asli orang Indonesia. Bukti shahih dari kekhawatiran ini, dapat terlihat jelas dari kontestasi kepentingan politik di Pilkada Jakarta, keberpihakan pemerintah terhadap kelompokkelompok Islam moderat, aksi terorisme yang tidak kunjung usai, hingga rencana pemerintah menghapus/membubarkan organisasi keagamaan yang berideologi kekerasan, baik berasal dari gerakan transnasional ataupun lahir atas inisiasi masyarakat Islam-Indonesia sendiri. Tentu, dalam konteks menanggapi kegelisahan ini, menurut penulis, pemerintah sudah melakukan hal yang benar. Artinya, pemerintah menginginkan sebuah konsep kenegaraan yang tidak keluar dari fondasi awal Indonesia dibangun. Pemerintah, pada satu sisi, juga berharap masyarakat mau 
berkerjasama untuk menghadirkan sebuah negara yang damai, tentram, dan mensejahterakan.

Kendatipun, mereka (kelompok-kelompok yang hari ini menjadi perhatian pemerintah) harus diyakini jika mereka tidak akan pernah diam. Mereka akan tetap melakukan counter-movement, melalui jalur-jalur yang tersedia di era demokrasi, supaya masih tetap bisa melaksanakan apa yang sudah menjadi keyakinan dan ideologi mereka. Misalnya, mereka menyangsikan bahwa kebijakan pemerintah untuk kedamaian dan stabilitas kehidupan social, ekonomi, serta politik. Mereka juga melakukan perlawanan melalui kampanye bahwa pemerintah sudah menyalahi nilainilai Negara demokrasi, dan masih banyak cara lain yang mereka kerjakan. Oleh karena kontestasi ini tidak mudah diselesaikan, kedua belah pihak menempuh kampanye untuk menarik hati masyarakat sekitar. Keith A Nitta pernah menyebutkan bahwa drama pemerintah dan civil society di ruang publik merupakan keniscayaan di sebuah negara demokrasi. Siapapun yang memenangkan kontestasi tersebut, maka dia akan mendapatkan dukungan untuk menjalankan idealismenya. ${ }^{1}$ Maka dari itulah, hari ini, termasuk acara-acara symposium, konfrensi, dan seminar di dunia akademik disumuki oleh kontestasi ide-ide tersebut.

Posisi tulisan ini, tentu tidak bermaksud untuk menghilangkan apa yang sudah menjadi kontestasi tersebut. Lebih kecil dari itu, tulisan ini sekedar ingin memaparkan bagaimana semua orang bisa memahami apa yang sedang terjadi di Indonesia. Bagaimana gerakan-gerakan transnasional (termasuk di dalamnya yang berideologi radikal) ambil bagian di Indonesia. Bagaimana umat Islam Indonesia memahami karakter asli kehidupan mereka. Apa kekuatan yang dimiliki oleh umat Islam Indonesia. Serta bagaimana strategi dan tahapan-tahapan yang bisa dilakukan agar pemerintah, khususnya, dan masyarakat Islam-Indonesia, umumnya, mampu membendung dan mengantisipasi efek negatif dari gerakan-gerakan trans-nasional. Tulisan ini juga, sedikitnya, akan memberikan kontribusi terhadap pemangku kebijakan untuk memformulasikan ramalan kebijakan yang paling efektif dalam menangkal ide, gerakan, dan politik transnasional tersebut. Dari sudut sistematika,

${ }^{1}$ Keith A. Nitta, The Politic of Structural Education Reform (New York: Routledge, 2008), 1-2 
penulis akan memulai dari kajian terhadap tantangan gerakan transnasional terhadap eksistensi identitas Islam-Indonesia. Bingkai moderatisme Islam-Indonesia, dan memposisikan pondok pesantren (lembaga pendidikan Islam secara umum) sebagai institusi strategis melawan gerakan tersebut.

\section{Kontestasi Trans-Nasionalisme; Sebaran Ide, Ideology, dan Institusi}

Gambaran utuh mengenai terminologi gerakan Trans-nasional, sebagai hasil kajian ilmiah, memang sulit untuk dilacak. Bahkan Masdar Hilmy hanya menyebuntukan bahwa terminologi Trans-nasionalisme hanya merupakan ungkapan dari dua tokoh gerakan Islam terbesar di Indonesia; yakni KH. Hasyim Muzadi sebagai mantan ketua PBNU dan Syafi'i Ma'arif mantan ketua Muhammadiyah². Terminologi Trans-nasionalisme memang sempat diungkapkan oleh KH. Hasyim Muzadi untuk menggambarkan pelbagai tipologi gerakan baru yang mulai menyebar di Indonesia yang disupport oleh kekuatan di luar negeri. Lebih tepatnya beliau ingin menyebuntukan bahwa radikalisme yang terjadi di Indonesia terjadi karena dibantu oleh beberapa negara-negara maju, dan tidak murni keinginan orang IslamIndonesia ${ }^{3}$. Sedangkan Syafi'i Maarif memasukkannya dalam kalimat bukunya yakni “....sorotan berikutnya atas HTI, berbeda dengan MMI yang bercorak Indonesia, HTI adalah gerakan politik. Islam Trans-nasional yang digagas oleb Taqiyuddin An-Nabhani ${ }^{4}$. Namun, beliau tidak menafsirkan organisasi apa saja yang dimasukkan dalam kategori gerakan Trans-nasional.

Dalam upayanya menjelaskan terminologi Trans-nasionalisme Islam sebagai nomenclature, Masdar Hilmy meminjam pengertian yang diungkapkan oleh J.R Bowen yang mencakup tiga hal; (a) pergerakan demografis. (b) lembaga keagamaan Transnasional. (c) perpindahan gagasan atau ide. ${ }^{5}$ Pengertian pertama bermakna bahwa Trans-nasionalisme berarti pergerakan lintas negara. Terma kedua memiliki makna perangkat kelembagaan yang memiliki jejaring internasional. Sedangkan yang terakhir

\footnotetext{
${ }^{2}$ Masdar Hilmy "Akar-akar Trans-nasionalisme Islam Hizbut Tahrir Indonesia (HTI)", Islamica, Vol. 8, No. 2 (September 2011), 1-2.

${ }^{3}$ KH. Hasyim Muzadi Rekaman Seminar Radikalisme Islam di UI Depok.

${ }^{4}$ Syafi'i Maarif, Islam dalam Bingkai keindonesiaan, Sebuah Refleksi Sejarah (Bandung: Mizan, 2009), 191.

${ }^{5}$ Hilmy, Akar, 2.

32 | Tarbiyatuna: Jurnal Pendidikan Islam; Volume 11, Nomor 1, Februari 2018 p-ISSN: 2085-6539, e-ISSN: 2242-4579
} 
adalah perpindahan idea tau gagasan dari kelompok atau individu dari negara yang satu ke negara yang lain.

Jikalau melihat makna terminologis trans-nasionalisme dalam arti yang demikian maka ada kesamaan persepsi pula di khalayak umum bahwa gerakan Transnasionali atau Trans-nasionalisme adalah sebuah gerakan yang melintasi batas negara (nation), berbasis pada umat Islam di seluruh dunia, didominasi oleh pemikiran skriptualis, radikal, fundamental, dan bergagasan berbeda dengan konsep nation-state ${ }^{6}$ Sebagai contohnya adalah kelompok gerakan Ikhwanul Muslimin, gerakan yang sekarang memegang kekuasaan di Mesir ini, ingin mengembalikan kekuatan Islam sebagai basis politik dan keluar dari hegemoni konsep demokrasi yang dikembangkan masyarakat Barat.

Dalam bingkai pemikiran G. Fealy dan Bubalo menyebutkan bahwa ada upaya 'deteritorialisasi' Islam agar bisa menembus pada dimensi global' ${ }^{7}$ Tidak ada hal apapun yang hanya memiliki satu dimensi. Semua hal hamper memiliki dimensi ganda, ada yang menganggap positif, adapula yang beranggapan negative. Sama halnya dengan eksistensi gerakan Trans-nasional, ada yang beranggapan bahwa gerakan ini merupakan ancaman bagi masyarakat tertentu dan dianggap 'nyeleneh' (menyalahi) nilai kebudayaan local, bahkan Islam. Namun, adapula anggapan bahwa gerakan Trans-nasional ini merupakan upaya untuk mengembalikan nilai-nilai keagamaan yang dikikis oleh gerakan lainnya, semisal liberalism, westernisasi dan lain sebagainya.Target utama dari gerakan deteritorialisme ini adalah mengubah budaya asli negara muslim setempat, dengan pandangan baru yang dianggap dimiliki oleh Islam murni. Artinya, umat Islam yang berbeda dengan pandangan kelompok gerakan ini dianggapnya salah, serta tidak menerima akulturasi kebudayaan Islam dengan local wisdom yang dimiliki negara Islam tertentu.

Diakui atau tidak, trans-nasionalisme, islam trans-nasional, atau gerakan Islam trans-nasional sudah berwujud dan banyak ditemukan. Meskipun secara keilmiahan terminologi tersebut berbeda-beda disebutnya. Islam, sebagaimana wujudnya, memang merupakan agama global yang tidak hanya dianut oleh negara tertentu.

${ }^{6}$ Hilmy, Akar, 6.

${ }^{7}$ Situs Resmi Hizbut Tahrir Indonesia, http://hizbut-tahrir.or.id/tentang-kami/ (10 Februari 2013). 
Persinggungan nilai dan global akan terus terjadi meskipun ditanggapi secara berbeda-beda. Meminjam istilah, Fethullah Gulen Islam, melalui nilai universalismenya, memang tidak bisa dimiliki oleh kalangan tertentu. Iran memiliki tradisi sendiri untuk merayakan tauladannya, 'Ali bin Abi Tholib, sedangkan di negara lain mereka juga punya tradisi lain yang dianggapnya merupakan bagian dari Islam, begitu juga dengan Turki, yang dulunya dibangun di atas narasi sufisme ${ }^{8}$.

Anggapan bahwa Trans-nasionalisme sebagai ancaman sudah disebutkan di atas, misalnya ungkapan Syafi'i Ma'arif, dan KH. Hasyim Muzadi. Sedangkan bagi mereka yang mendukung gerakan ini juga menganggap bahwa ungkapan yang disebutkan dua tokoh di atas salah. Ima'il Yusanto, juru bicara Hizbut Tahrir Indonesia (HTI), mengatakan bahwa:

"Sikap asal menolak ideologi Trans-nasional adalah tidak tepat. Apalagi bila yang dimaksud adalah (ideologi) Islam. Sikap yang benar adalah bahwa kita harus menolak ideologi yang jelas-jelas telah menimbulkan kerusakan pada negeri ini; menyengsarakan rakyatnya dan bakal menghancurkan persatuannya. Itulah ideologi Trans-nasional kapitalisme global yang dikomandani oleh AS. Kejahatan ideologi ini dengan sangat gamblang diuraikan oleh Vedi R Hadiz dalam Empire and Neoliberalism in Asia (2006). Intinya, AS semakin mengupayakan sebuah disain kebijakan berskala global, utamanya di bidang politik dan ekonomi, yang dapat memberikan jaminan bahwa dominasi atas planet ini tetap berada dalam genggaman AS, tidak peduli apakah kebijakan global itu menyengsarakan rakyat di banyak negara atau tidak.",

Bagi para pendukungnya, implikasi positif yang dihasilkan dari gerakan Transnasional adalah keberadaannya yang bisa menghadirkan Islam sebagai worldview dan Islam benar-benar menjadi jalan keluar dari kehidupan masyarakat. Islam dianggapnya sebagai panutan yang melintasi seluruh batas-batas territorial. Dengan keberadaan gerakan Trans-nasional, Barat melalui agenda "westernisasinya" merasa mendapatkan tangtangan yang serius.

Adapun beberapa implikasi negatif dari gerakan Trans-nasional adalah :

1. Gerakan trans-nasional berkarakter memaksakan kehendaknya untuk mengadopsi apa yang sudah diyakininya benar.

${ }^{8}$ Fethullah Gulen, Love and Tolerance (New Jersey: Tughra Book, 2009), 223.

${ }_{9}$ Isma'il Yusanto, Islam Trans-nasional, http://hizbut-tahrir.or.id/2007/07/19/bahaya-ideologi-Transnasional/ (diakses 4 Februari 2013).

34 | Tarbiyatuna: Jurnal Pendidikan Islam; Volume 11, Nomor 1, Februari 2018 p-ISSN: 2085-6539, e-ISSN: 2242-4579 
2. Gerakan trans-nasional, pada umumnya, enggan untuk menghargai kearifan local sebuah teritori negara.

3. Gerakan trans-nasional juga memiliki tradisi dan kebudayaan yang berbeda dengan kebudayaan setempat.

4. Terkadang, Gerakan Trans-nasional menggunakan cara-cara anarkisme untuk menyebarkan pemahamannya.

Terlepas dari apa yang sudah dipaparkan di atas, dalam wujudnya (baca; antropologis), transnasionalisme bisa berbentuk kelembagaan gerakan dan pendidikan. Wujud gerakan dan lembaga pendidikan merupakan dua model paling efektif untuk membangun ide tersebut berjalan sebagaimana mestinya. Lembaga pendidikan sebagai mesin gerakan Trans-nasional berarti memposisikan lembaga pendidikan sebagai bagian strategi untuk menyebarkan ideologi trans-nasionalnya. Setidaknya ada beberapa lembaga pendidikan Islam yang dibentuk untuk menampung para pengikut gerakan tersebut. Berkaitan dengan ini, penulis akan memberikan gambarannya melalui hasil-hasil penelitian: salah satunya adalah milik Jajang Jahroni dan Imdadur Rahmat. Objek penelitan Jajang terfokus pada konsep pendidikan LIPIA Jakarta yang merupakan join project dengan Arab Saudi.

Laporan Jajang dari LPPIM UIN Jakarta memasukkan Lembaga pendidikan Indonesia Arab Suadi LIPIA Jakarta sebagai bagian kategori lembaga pendidikan Islam yang di support oleh gerakan Wahabi di Indonesia. Dia menjelaskan:

"...LIPIA, is a Saudi education project and its network with Indonesian greduates. These returning greduates are currently serving in various positions such as teachers and preachers. In the course of time they have maintained relation with Saudi, from which they obtain financial supports. It focuses on student who studied in Saudi in recent periods precisely in the 1980s, 1990s, and 2000s. Their understanding of sharia have changed over the time depending its contexts" 10 .

Lebih lengkapnya dia juga menyebut bahwa eksistensi lembaga tersebut untuk mendirikan identitas baru. Yakni identitas salafisme yang memiliki karakter ritus dan habitus berbeda dengan karakter keislaman di Indonesia. Dia juga menambahkan :

${ }^{10}$ Jajang Jahroni, “Annual Conference on Islamic Studies (ACIS) ke-12 tanggal 5-8 di Surabaya” dalam The Political Economy of Knowledge: Sharia and Saudi Scholarship in Indonesia, (Jakarta: PPIM UIN,2012), 8. 
"The ideology of Salafism is further disseminated among the others trough prayer. Prayer is the most important ritual in Islam, and mosque serves the locus where identity, it is better to perform it collectively. By performing collective prayers, student are involved in face to face communication with others. Conversion, expression, shaking hand, kissing, hugging and patting are quite common and ritualized. Performing collective prayer will give deep impact and rise strong in group feelings on each member of the believers. ${ }^{11}$

Dari dua kutipan di atas, terlihat betul bahwa ada kepentingan asing dalam pendirian lembaga pendidikan Islam (political economy of knowledge) di LIPIA ini. Pendanaan Arab Saudi untuk mengembangkan LIPIA terbagi menjadi beberapa bentuk: pertama, dalam bentuk beasiswa bagi siswa atau mahasiswa yang tidak mampu.Kedua, gaji yang berlimpah luah bagi guru atau staff pengajar ${ }^{12}$. Tapi, pastinya, ada syarat yang mesti dipenuhi yakni dengan menjadi bagian dari penyebaran ideologi Wahabi di Indonesia.

Selain laporan Jajang Jahroni yang mengangkat eksistensi Wahabi di Indoesi, Imdadud Rahmat juga menggaris bawahi kesamaann sistem pendidikan yang disediakan oleh partai PKS dengan ikhwanul Muslimin yang berbasis di Mesir. Kesamaan tersebut terletak pada system kadarisasi dan gerakan tarbiyah.

“...sistem pengkaderan Tarbiyah PKS merupakan adopsi dan pengembangan dari model pengkaderan Tarbiyah Ikhwanul Muslimin. Pola tarbiyah PKS bisa dikatakan mengadopsi prinsip-prinsip dasar dan sturktur umum Tarbiyah Ikhwanul Muslimin. Hal ini meliputi landasan filosofis, ideologis, dan mabda' (prinsip) keagamaan, tujuan dan target pendidikan, manhaj (metode) dan penetapan, sarana-sarana pendidikan, serta materi pendidikan yang dipakai. Tarbiyah PKS hanya melakukan adaptasi terbatas terkait dengan materi pendidikan serta menghilangkan sarana pendidikan yang tidak sesuai dengan kondisi dan kebutuhan di Indonesia." 13

Perbedaan antara dua hasil atau kosntruksi penelitian di atas, LIPIA adalah project Arab Saudi dan tidak berimbas pada sebuah gerakan politik. Sedangkan penelitian Imdad, lebih fokus pada garis politik PKS dan sebagian saja membahas tentang pendidikan atau Tarbiyah. Satu hal lagi, pendidikan di PKS tidak terbentuk dalam lembaga formal, melainkan pada pembasisan dan pengkaderan berbasis pada kaderisasi organisasi di beberapa kampus di Indonesia.

11 Jahroni, The Political Economy of Knowledge, 9.

12 Jahroni, The Political Economy of Knowledge, 10.

${ }_{13}$ M. Imdadun Rahmat, Ideologi Politik PKS (Yogyakarta: Elkis, 2008), 242.

36 | Tarbiyatuna: Jurnal Pendidikan Islam; Volume 11, Nomor 1, Februari 2018 p-ISSN: 2085-6539, e-ISSN: 2242-4579 
Penelitian terdahulu mengenai relasi antara dunia pendidikan dengan gerakan Trans-nasional sempat diulas lengkap oleh Greg Fealy dan Anthony Bubalo. Dalam hasil penelitiannya, dia menyebut LIPIA sebagai project ilmu pengetahuan yang didanai oleh Arab Saudi untuk menyebar luaskan ajaran Wahabisme dan Salafisme ${ }^{14}$. Selain dua lembaga ini, dia mengutip laporan, ICG tentang salafisme dan organisasi salafi yang menerima dukungan dari luar negeri adalah Yayasan al-Shofwah dan Wahdah Islamiyah ${ }^{15}$

Setidaknya inilah relasi aktif lembaga pendidikan Islam dengan gerakan Islam Trans-nasional. Sebenarnya masih banyak bentuk-bentuk lembaga pendidikan lainnya yang mendapatkan sponsor dan dukungan finasial, sarana pendidikan, dan lainnya, di Indonesia. Karena, di era yang seperti ini, tak lagi ada batasan bagi masyarakat untuk meminta dan menerima bantuan khususnya dalam konteks dunia pendidikan. Demokrasi menjadikan globalisme mendapatkan ruang yang sangat luas.

\section{Identitas Moderatisme Islam-Indonesia; Learning From NU and Muhammadiyah}

Pada bagian ini, penulis ingin mengungkap bagaimana semestinya Islam Indoensia harus di bangun. . Ahmad Syafi'i Maarif misalnya, memberikan catatan penting bagaimana Islam (bacal organisasi keislaman di Indonesia) harus hadir dan ambil bagian untuk menciptakan Islam yang bisa menjadi rahmat seluruh umat. Dia menegaskan:

“...harapan masyarakat luas, terutama saudara-saudara kita sebangsa yang tidak seagama dengan kita masih menaruh harapan besar kepada Muhammadiyah dan NU untuk tetap berperan sebagai payung pelindung eksistensi mereka yang sering "diteror" oleh kelompok-kelompok yang mengesankan dirinya sebagai yang paling relijius dan paling dekat dengan Tuhan, jika bukan telah mengambilalih peran Tuhan tentang kebenaran. Indonesia masih beruntung karena arus besar Islam di sini telah mengkristal dalam kultur Muhammadiyah dan kultur NU yang moderat, terbuka, dan modern. Jika terasa kelemahan dalam kultur ini adalah karena Muhammadiyah dan NU kurang agresif dalam upaya memasarkan cita-cita Islam yang memayungi semua suku bangsa, penganut agama, dan siapa pun yang hidup di bumi Nusantara ini. Di saat-saat kritikal, sikap agresif tetapi

${ }^{14}$ Greg Fealy dan Bubablo, Jejak Kafilah, 94

15 Greg Fealy dan Bubablo, Jejak. Kafilah, 99 
terukur perlu juga ditunjukkan agar pihak lain tidak menilai kita telah kehabisan amunisi untuk berperan sebagai payung pelindung dan tenda besar bagi semua." 16

Sebagaimana diketahui, Syafi'i Ma'arif merupakan ketua Muhammadiyah yang hingga hari ini sangat khawatir dengan menguatnya gerakan transnasional yang menghinggapi Bumi Nusantara. Termasuk di dalamnya para cendikiawan Muhammadiyah lainnya yang mengetahui bagaimana setting global akan menggerogoti identitas kebangsaan yang ada di Indonesia. Dari kutipan di atas, menurut penulis terdapat satu keyword penting yakni "Kultur Moderat, Terbuka dan Modern," yang harus didengungkan oleh para intelektual muslim di Indonesia. Kegelisahan serupa diungkapkan oleh Amin Abdullah, dia menyebutkan bahwa;

“....Tantangan yang dihadapi Muhammadiyah pada abad pertama usianya pasti berbeda dari abad kedua usianya. Meskipun, kontinuitasnya antara keduanya tetap ada. Untuk itu, paradigma, model, dan strategi tajdidnya juga harus disesuaikan dengan perkembangan terbaru discourse keislaman baik dalam teori maupun praktek. Muhammadiyah harus melakukan upaya pembaharuan from within, yang meliputi strategi pembaharuan gerakan pendidikan yang selama ini digelutinya, mengenal dengan baik dan mendalam metode dan pendekatan kontemporer terhadap studi Islam dan Keislaman era klasik dan lebih-lebih era kontemporer, mendekatkan dan mendialogkan Islamic Studies dan Religious Studies, bersikap inklusif terhadap perkembangan pengalaman dan keilmuan generasi mudanya, terbuka, mengenalkan dialog antar budaya dan agama di akar rumput, memahami cross-cultural values dan multikulturalitas, dalam bingkai fikih NKRI, dan begitu seterusnya. Tanpa menempuh langkah-langkah tersebut, gerakan pembaharuan Islam menuju ke arah terwujudnya Masyarakat dan Peradaban Utama di tanah air ini, tentu akan mengalami kesulitan bernapas dan kekurangan oksigen untuk menghirup dan merespon isu-isu sosial-keagamaan global dan isu-isu peradaban Islam kontemporer. Untuk konteks keindonesiaan, Ikon perjoangan meraih "Islam yang berkemajoean" sepertinya tetap menarik untuk diperbincangkan dan didiskusikan sepanjang masa. Dengan begitu kontinuitas dan kesinambungan perjoangan antara generasi abad pertama dan generasi penerus abad kedua masih terpelihara, sebagaimana dicanangkan dan dipesankan oleh founding fathers Muhammadiyah terdahulu. ${ }^{17}$

16 Ahmad Syafi'i Maarif "Menata Ulang Posisi Muhammadiyah Sebagai Gerakan Keagamaan dan Kemasyarakatan di Tengah Dinamika Kehidupan Berbangsa dan Bernegara". Diakses melalui http://blog.beswandjarum.com/rosyidah/2010/06/12/menata-ulang-posisi-muhammadiyah-sebagaigerakan-keagamaan-dan-kemasyarakatan-di-tengah-dinamika-kehidupan-bangsa/ Pada 23 Mei 2017

${ }_{17}$ Makalah Amin Abdullah dalam Pengajian Ramadhan di Majelis Tarjih Muhammadiyah Yogyakarta Pada Yogyakarta, 21 Nopember 2009 (diakses melalui web resmi muhammadiyah) 
Masdar Hilmy mengatakan bahwa keberadaan NU dan Muhammadiyah sebagai organisasi moderat tidak bisa dilepaskan karena memiliki ciri khas sepadan dalam lingkup gerakan. Pertama, ketidaksepahaman kedua kelompok ini terhadap gerakan-gerakan Islam yang mendahulukan kekerasan untuk menyelesaikan masalah di masyarakat. Kedua, kedua organisasi ini tidak setuju dengan Negara Islam, sebuah isu laten yang digagas oleh kelompok radikal. Bagi keduanya, NKRI, Pancasila, UUD 45, dan Bhinneka Tunggal Ika sudah dianggap cukup mewakili nilai-nilai keislaman yang bervisi Islam rahmat bagi semua umat. Oleh karena itu, dia memberikan saran cetak biru bagaimana moderatisme dua organisasi ini, bisa ditonjolkan. Menurutnya, pertama NU dengan kemampuan kharismatik dan kelenturannya mengakomodasi budaya Islam-Indonesia harus terus meminta bantuan pemikir Muhammadiyah untuk menopang kreatifitas dan inovasi kekayaan metodologis-ijtihadi yang dimilikinya. Kedua, pada tataran praktis, keduanya harus berani tampil ke permukaan untuk menghadirkan hadharah Islam-Indonesia. Tidak sekedar mengadopsi dan mengadaptasi pandangan keislaman luar menjadi kerangka cultural dan metodis di dalam organisasi masing-masing. Melalui cara yang seperti itu, identitas IslamIndonesia akan menjadi tajuk yang bisa dicontoh oleh seluruh dunia. ${ }^{18}$

Biyanto, dalam opininya pun menegaskan bahwa persinggungan Muhammadiyah hari ini tidak lagi sekedar persoalan pengembangan intelektualisme dan perbincangan teologis. Kendati, nilai-nilai tersebut harus terus dijaga sebagai asas perjuangan yang sudah digariskan secara organisatoris. Lebih jauh dari itu, ada persoalan lebih genting untuk didahulukan, yakni; menengahi sikap Islam ekstrim di Indonesia. Satu kelompok bermotifkan carapandang yang terlalu liberal, satu kelompok lainnya terlalu fundamentalis, bahkan cenderung radikal. Posisi Muhammadiyah, menurutnya, harus bisa menjadi mediator dengan melakukan management of ideas dari beberapa kelompok yang berseberangan tersebut. Dia mengatakan pula bahwa:

"Yang perlu dilakukan Muhammadiyah pada berbagai mazhab pemikiran (school of thought) adalah mengajak mereka untuk bergerak ke posisi tengah

\footnotetext{
18 Masdar Hilmy "Whither Indonesia's Islamic Moderatism?; Reexamination on Moderate Vision Muhammadiyah and NU. Dalam Journal of Indonesian Islam Vol 07, No 1, 2013 (LSAS; UIN Sunan Ampel Surabaya), 25-44
} 
(al-wasath ). Ajakan untuk bersikap moderat ini akan efektif jika ditempuh melalui dialog yang tulus dan tidak saling mengklaim kebenaran. Jika dialog ini dilakukan secara berkelanjutan, pada saatnya kita akan menyaksikan wajah Islam Indonesia yang moderat dan toleran terhadap berbagai keragaman. Karena itulah, posisi tengah (median position) inipentingsebagaitempat berpijak berbagai mazhab pemikiran. Jika Muhammadiyah berhasil menjadi mediator yang baik bagi berbagai mazhab pemikiran keagamaan, ini akan menjadi kontribusi yang luar biasa bagi perkembangan Islam Indonesia. Untuk kepentingan ini, jelas dibutuhkan seperangkat ilmu. Karena itulah, Muhammadiyah harus meneguhkan ideologinya agar mampu menjadi gerakan praksis sekaligus gerakan intelektual. Akhirnya diucapkan selamat milad bagi warga Muhammadiyah. Semoga dengan usia lebih dari satu abad, matahari Muhammadiyah bersinar semakin terang. Dengan demikian, Muhammadiyah mampu menjadi gerakan pencerahan (al-harakah al-tanwiriyah) bagi umat, bangsa, dan negara. ${ }^{19}$

Dari sini, Nahdlatul Ulama' ataupun Muhammadiyah sudah sangat tegas berkeinginan untuk mengembalikan Islam-Indonesia sebagai model keislaman yang sangat akulturatif dan berkemajuan. Oleh karenanya, untuk menangkal seluruh gerakan transnasional yang ada, maka diperlukan upaya yang sungguh-sungguh dan berpegang pada nilai-nilai yang sudah dikembangkan bersama di dalam kerangka berfikir rasionalis, progresif, dan moderat.

\section{Pesantren and Schooling Islam; Rebuilding Religious-Nationalism}

Jika di atas penulis lebih condong membahas bagaimana Muhammadiyah menanggapi gerakan-gerakan transnasionalisme, maka di bagian ini penulis ingin mengungkapkan bagaimana semestinya kondisi lembaga pendidikan dan peranannya dalam membangun masyarakat yang moderat, inklusif, toleran, dan multicultural. Pesantren merupakan institusi pendidikan yang berperan secara intensif dalam penyebaran Islam di Nusantara khususnya di pulau Jawa, bahkan menjadi media utama gerakan Islam dalam pembinaan moral bangsa Indonesia. ${ }^{20}$ Karakter pesantren yang akomodatif terhadap pola kehidupan masyarakat setempat dalam melakukan transformasi sosio-kultural, bahkan format pendidikan pesantren dipandang sebagai

\footnotetext{
19 Biyanto Meneguhkan Ideologi Muhammadiyah diakses melalui https://nasional.sindonews.com/read/925679/18/meneguhkan-ideologi-muhammadiyah$1416288457 / 13$ pada 23 Mei 2017

20 Arif, Pendidikan, 165. Lihat juga Dhofier, Tradisi, 62

40 | Tarbiyatuna: Jurnal Pendidikan Islam; Volume 11, Nomor 1, Februari 2018 p-ISSN: 2085-6539, e-ISSN: 2242-4579
} 
islamisasi lembaga pendidikan yang telah ada sejak masa Hindu-Budha, ${ }^{21}$ karena ada kemiripan antara pesantren dengan tradisi yang ada pada padepokan dalam tradisi Hindu-Budha; yaitu konsentrasi pendidikannya pada pembelajaran agama, gurunya tidak digaji, adanya penghormatan yang besar terhadap guru, dan letaknya yang berada di luar perkotaan. ${ }^{22}$ Posisi pesantren yang dipandang sebagai kelanjutan dari lembaga pendidikan Jawa kuno yang bernama pawiyatan, di mana Ki Ajar sebagai pengajar dan Cantrik sebagai murid tinggal dalam satu komplek dan di sanalah terjadi proses belajar mengajar ${ }^{23}$, maka sangat beralasan bila pendidikan pesantren dipandang sebaga institusi yang menjadi salah satu kekuatan dalam mempercepat penyebaran Islam di Indonesia secara damai.

Ada tiga karakter utama budaya pesantren yang lebih mendekati ideologi perdamaian. Pertama, Modeling. Karakter ini dalam terma keislaman dapat diidentikkan dengan uswah b\}asanah, dimana proses transformasi nilai tidak hanya menggunakan bahasa lisan melainkan melalui percontohan dalam bentuk tingkah laku. Para santri dan masyarakat melakukan proses identifikasi diri pada Kyai yang dijadikan tokoh dan panutan dalam berprilaku. Pola modeling dalam pendidikan pesantren ini, mendapat tempat di masyarakat Jawa karena ada kesesuaian dengan sistem nilai Jawa yang telah lama mengakar dalam budaya Jawa; yaitu paternalism dan patron-client relation. ${ }^{24}$

Kedua, Cultural maintenance. Pendidikan pesantren menggambarkan adanya kontinuitas budaya, tanpa melakukan perombakan fondamental terhadap budaya lokal tapi tetap bersandar pada ajaran dasar Islam. Para Kyai menjadi agent of social change lebih menggunakan pendekatan kultural, bukan politik struktural apalagi tindakan arogansi dan kekerasan. Apa yang dilakukan para Kyai melalui pendidikan pesantren bukan intervensi budaya melainkan perembesan budaya atau akulturasi. ${ }^{25}$ Pesantren yang menjadi pusat proses dialogis antara tradisi lokal dan ajaran Islam, melalui proses akulturasi, asimilasi, dan adaptasi tradisi lokal yang animis dan nilai-

${ }^{21}$ Madjid, Merumuskan, 3.

${ }^{22}$ Karel A. Stenbrink, Pesantren Madrasah Sekolah : Pendidikan Islam dalam Kurun Modern, Jakarta: LP3ES, 1994), 20-21.

${ }^{23}$ Daulay, Sejarah, 21.

${ }^{24}$ Mas'ud, Memahami, xix-xx.

${ }^{25}$ Mas'ud, Memahami, xxii 
nilai Islam, telah menghasilkan tradisi baru Islam Indonesia yang selalu membawa sikap harmonis dalam strategi pendidikan dan pengembangannya. ${ }^{26}$ Karakter kedua ini, tercermin pula dalam penggunaan refernsi utama pendidikan pesantren, yang tetap mempertahankan karya klasik atau yang disebut dengan Kitab Kuning. Penggunaan Kitab Kuning dalam pendidikan pesantren yang ditransmisikan dari generasi ke genarasi, menunjukkan adanya upaya pendidikan pesantren untuk melestarikan warisan budaya Islam periode awal dan pertengahan. ${ }^{27}$

Ketiga, Budaya Keilmuan Yang Tinggi. Menuntut ilmu di pesantren tidak dikenal batasan umur, dan batasan waktu. Tidak jarang seseorang yang sudah beranak cucu, masih belajar di Pesantren terutama dalam kegiatan pengajian Ramad \{an atau yang dikenal dengan istilah pengajian kilatan. Dalam tradisi pesantren juga dikenal santri kelana, yaitu santri yang melakukan rib\}lah dalam pencarian ilmu dari satu pesantren ke pesantren lainnya, bahkan tidak sedikit dari komunitas pesantren yang melakukan rib\}lah dalam pencarian ilmu sampai ke luar negeri. ${ }^{28}$

Dalam prespektif kebangsaan, Pesantren hadir sebagai pusat pendidikan kebangsaan, dengan mendidik santri dan anak bangsa lainnya mandiri tidak hanya dalam ekonomi dan politik, melainkan mandiri juga dalam bidang kebudayaan dan pengetahuan. Pesantren mengembangkan pendidikan kebangsaan melalui pembiasaan hidup dalam kebersamaan baik dalam asrama, maupun di luar asrama dengan anakanak bangsa tanpa memperhatikan latar suku, bahasa, bahkan agamanya. Mereka dididik untuk saling berinteraksi secara harmonis di antara berbagai komunitas bangsa yang heterogin. Dan apabila ada perselisihan, mereka diminta berdamai dengan mediasi para Ulama pesantren. ${ }^{29}$

Dari pesantren, para pegiat pergerakan belajar tentang non kooperatif, menolak kerjasama dengan Belanda. Sikap pesantren untuk menjadi dirinya sendiri, kesediaan untuk hidup bersahaja dalam kesederhanaanya, pembiayaan pendidikan dibangun di atas kekuatan sumber daya alam yang ada disekitarnya, dari hasil

\footnotetext{
26 Sholeh, Dinamika, xxviii.

27 Mas'ud, Memahami, xxiii.

28 Mas'ud, Memahami, xxiii-xxiv. Lihat juga Abuddin Nata, Sejarah Sosial Intelektual Islam dan Institusi Pendidikannya (Jakarta: Raja Grafindo Persada, 2012), 310-311.

29 Baso, Pesantren, 50-51.
}

42 | Tarbiyatuna: Jurnal Pendidikan Islam; Volume 11, Nomor 1, Februari 2018 p-ISSN: 2085-6539, e-ISSN: 2242-4579 
pertanian, perkebunan dan peternakan, tidak memandang penting dana subsidi pemerintah kolonial, Ki Hajar Dewantara sebagaimana dikutip Ahmad Baso, memandang sikap pesantren tersebut sebagai bentuk kemerdekaan pesantren. ${ }^{30}$

Pesantren dipandang oleh pegiat peregerakan nasional, sebagai lembaga pendidikan yang banyak memberikan kontribusi dalam membentuk sifat dan karakter pengajaran nasional yang membedakan dengan pengajaran kolonial. Kedekatan Pesantren dengan masyarakat paling bawah, memperkaya pendidikan kultural, kerohanian masyarakat, memupuk solidoritas dan mengukuhkan semangat kebangsaan yang bertumpu pada tiga nilai dasar; persatuan, kemandirian dan kemerdekaan. ${ }^{31}$ Pendidikan pesantren dengan sistem asrama (pondok), berhasil mempersatukan dan merekatkan hubungan anak-anak bangsa dari semua lapisan masyarakat, baik anak petani, anak saudagar, anak bangsawan, semua berkumpul dalam ikatan nilai persamaan dan kebersamaan dalam kepemimpinan seorang kyai yang sederhana dan merakyat, sehingga pada saat mereka kembali ke masyarakatnya dengan profesi yang beraneka ragam, tetap merasa dalam kesatuan karena perikatan lahir dan batin yang tertanam sejak ada dalam pendidikan pesantren. Sehingga kehidupan bangsa dari lapisan apapun tidak tercerai berai, tidak terpisah satu sama lainnya. ${ }^{32}$

Pada masa pergolakan nasional di tahun 1930 an, pada saat itu aktivitas pergerakan nasional hidup di balik tembok-tembok pesantren, para aktivis pergerakan menjadikan pesantren sebagai oase perlindungan dari kejaran polisi Belanda. Pesantren tidak hanya menjadi pusat pendidikan kebangsaan, melainkan menjadi basis pergerakan nasional dalam membangun semangat kebangsaan dalam melawan segala bentuk penjajahan. ${ }^{33}$ Membaca fakta sosial keterlibatan pesantren dalam pergerakan nasional melawan penjajahan, dapat dikatakan bahwa pesantren memiliki andil dalam mengantarkan Indonesia Merdeka, Dan bisa dipahami apabila sampai saat ini, komunitas pesantren terus bergerak dalam mengisi kemerdekaan dalam berbagai bidang atau aspek pembangunan, tidak hanya dalam bidang pendidikan,

\footnotetext{
30 Baso, Pesantren, 30-31.

31 Baso, Pesantren, 32.

32 Baso, Pesantren, 36.

33 Baso, Pesantren, 40-41.
} 
dakwah, dan sosial yang menjadi khittah perjuangannya, melainkan juga di bidang politik yang merupakan medan baru sebagai bentuk respon pesantren terhadap situasi yang mengitarinya, dan sikap tanggunjawab pesantren terhadap eksistensi masyarakat bangsa di Nusantara ini.

\section{Building Multicultural-Society and Defending Transnationalism}

Pada bagian terakhir, penulis ingin menguatkan kembali apa yang semestinya bisa dilakukan untuk menangkal transnasionalisme. Dalam buku "Ilusi negara Islam" menyimpulkan ada beberapa rekomendasi strategis setelah membaca dan meneliti gerakan-gerakan trans-nasional agar bangsa indonesia tetap berpegang pada ideologi Pancasila dan UUD 45. Adapun rekomendasi tersebut adalah :

1. Mengajak masyarakat dan elit untuk bersikap terbuka, rendah hati, dan trus belajar agar bisa memahami sproitualitas, dan esensi ajaran agama, dan menjadi jiwa yang tenang.

2. Menghentikan dan mememutus mata rantai penyebaran paham ideologi garais keras melalui pendidikan yang mencerahkan.

3. Menyadarkan para elit dan masyarakat bahwa faham ideologi garis keras dan disebarkan oleh gerakan Islam Trans-nasional dari Timur Tengah bertentangan dengan Islam dan corak keberagamaan Islam-Indonesia yang santun, toleran, dan moderat.

4. Memperjuangkan dan melestarikan dan mewujudkan pancasila yang merefleksikan syari'ah

5. Bekerjasama dan mendorong para praktisi pendidikan dari tingkat dasar, menengah, dan tinggi untuk mengajarkan kekayaan dan nilai luhur bangsa Indonesia.

6. Mewujudkan institusi pemerintah yang bersih adil, dan taat hukum, agar tidak menjadi komoditas sensitif yang bisa dikembangkan sebagai isu untuk menggulingkan sistem demokrasi dan pancasila yang sudah dianut.

7. Menumbuhkan dan meningkatkan pemahaman dan kesadaran tentang esensi keislaman sebagai rahmat bagi mahluk hidup dan memobilisasi tokoh-tokoh agama agar menghidupkan warisan spritual bangsa. 
8. Membangun generasi cinta merah putih.

9. Menumbuhkan dan memberikan penyadaran bahwa budaya bangsa Indonesia tidak bertentangan dengan Islam ${ }^{34}$.

Melihat rekomendasi penelitian ini, tak ubahnya, memberikan peranan sangat besar terhadap beberapa kelompok masyarakat. Pertama, para pemangku kebijakan yang ada di pemerintahan untuk membentuk situasi kondusif di negara agar tidak menjadi komoditas politik. Kedua, peranan kiai, intektual, dan budayawan untuk terus mengeksplorasi dan memberikan pemahaman yang benar mengenai nilai-nilai luhur yang ada di Indonesia. Ketiga, lembaga pendidikan agar mampu mengajarkan nilainilai pendidikan Pancasila dan Islam yang benar.

Salah satu karya konfrehensif bagaimana pondok pesantren membingkai nilainilai toleransi menjadi bentuk budaya kepesantrenan adalah penelitian Mursyid. Dalam risetnya, dia membingkai pondok pesantren Tebuireng, Jombang dan Pondok Pesantren Nurul Jadid, Paiton, sebagai contoh pendidikan pesantren yang toleran dan pluralis. Temuan dia, menyebutkan bahwa ada beberapa kekuatan utama pondok pesantren untuk membingkai sikap toleran: Pertama, inklusivisme dan paradigma sufistik kiai. Kedua, budaya pesantren yang terbiasa membaca fenomena dari pelbagai tinjauan referensi. Ketiga, adanya basis nilai dasar yang diinternalisasi. Keempat, adanya kekuatan dukungan para pengajar yang juga memiliki basis keilmuan serupa. ${ }^{35}$ Paradigma inklusivisme kyai hadir dari kematangan berfikir keagamaan. Bukan sekedar pemahaman sosiologis-kultural. Dalam paparan datanya, dia menyebutkan pandangan $\mathrm{KH}$. Zuhri Zaini tentang takdir keragamaan yang sengaja dibuat oleh Allah SWTT agar manusia mampu menunjukkan sikap-sikap ketuhanan. Sikap-sikap yang menyayangi antar sesama manusia. Sikap-sikap yang tidak boleh menganggap bahwa pandangannya yang paling benar.

Adapun tradisi pesantren yang tidak hanya memiliki satu preferensi untuk menilai fenomena di luar pesantren, terbentuk dari paradigma kajian yang ada di pondok pesantren. Diakui atau tidak, pondok pesantren merupakan pasar dari semua

\footnotetext{
${ }^{34}$ Abdurrahman Wahid, edit Ilusi Negara Islam ekspansi gerakan Islam Trans-nasional di Indonesia (Jakarta : Wahid Institute, 2009), 229-232

${ }^{35}$ Wahid, Ilusi, 229
} 
madzhab, landasan pemikiran keislaman, hingga pada proses pertarungan ideologisasi keislaman. Tentu, kebiasaan pesantren mendiskusikan persoalan kekinian selalu dikontekskan pada cara berfikir yang berbasis pada kitab kuning dan pandangan ulama'-ulama' salaf. Namun, pada proses pelaksanaanya, para kyai umumnya, mencari format baru model penyampaian (dakwah) yang lebih elegan dan sesuai dengan bahasa-bahasa masyarakat sekitar. Para kyai, akan sangat sulit memahami diskursus toleransi yang dimaktub oleh akademisi. Tapi, mereka tahu bahwa subtansi dari toleransi adalah memahami perbedaan dan menghargai apapun yang terjadi di dalam masyarakat sebagai bentuk takdir ilahi yang tidak bisa diganggu gugat.

Selanjutnya, nilai-nilai dasar di PP. Nurul Jadid yang diinternalisasi melalui proses pembudayaan sikap menerima perbedaan dan perkembangan zaman. Dalam kurun sejarah yang panjang ini, PP. Nurul Jadid sudah memiliki keragaman proses internalisasi nilai yang sangat kuat berkaitan dengan nilai kebangsaan dan keindonesiaan. Para kyai di PP. Nurul Jadid tidak menjauhkan para santrinya dengan aktivitas kenegaraan. Para santri diwajibkan untuk mengikuti upacara kemerdekaan, berkumpul dengan lembaga-lembaga pendidikan formal lainnya di lapangan. Atau bahkan, mereka diundang untuk menghadiri upacara-upacara kenegaraan di lembaga pemerintahan. Hal ini penting untuk ditunjukkan. Pasalnya, salah satu faktor menguatkan radikalisme Islam dan intoleransi di lembaga pendidikan, diakibatkan oleh para peserta didik dijauhkan dari identitas asli Indonesia yang beragam. Di lembaga pendidikan tersebut, mereka cenderung dikenalkan dengan model keislaman yang satu frame dan ideologi tertentu.

Terakhir, Mursyid juga menegaskan pentingnya peran guru dan tenaga pengajar untuk melanjutkan cita-cita yang digariskan di dalam PP. Nurul Jadid. Dari data yang dipaparkannya, sudut pandang Kyai dan para guru bersinerji linier. Artinya, keberadaan KH. Zuhri Zaini yang memiliki kematangan intelektual dan spiritual, menjadikan para guru mengikutinya secara langsung. Sebagaimana teori Coleman, aktor individu menciptakan aktor korporat yang menjaga dan men-sustainable-kan nilai-nilai yang dipegang oleh aktor individu tersebut. Peran aktor korporat (baca; para guru) adalah menghadirkan paradigma Kyai yang inklusif dan toleran agar para 
santri mampu menterjemahkan perilaku santri dengan baik dan benar. Menurut pembacaan penulis, kerangka Pendidikan Toleransi ini bermuara pada tiga aspek; pertama, kyai dan guru yang inklusif. Kedua, budaya toleran yang ditampilkan (tolerance exibition) seperti yang sangat tampak di PP. Tebuireng Jombang, dimana Kyai dan para pengasuh yang lainnya memiliki andil membangun Indnonesia yang plural, seperti KH. Wahid Hasyim dan puteranya, KH. Abdurrahman Wahid. Sedangkan di PP. Nurul Jadid, para pengasuhnya tidak memiliki karakter menasional seperti yang ada di PP. Tebuireng Jombang, solusi yang dilakukan adalah menampakkan apa yang ada hari ini, khususnya dari ke-zuhudan dan ke-sufian KH. Zuhri Zaini. Ketiga, penanaman nilai-nilai yang sistematis dilakukan. Pada bagian ini, kedua lembaga ini memiliki problem serupa. Mereka tidak memiliki kurikulum yang spesifik terkait pola interaksi dan konstrutivisme di dunia pendidikan. Para santri dibiarkan 'liar' untuk memahami proses-proses yang sudah berjalan serta dijalankan oleh para pendiri dan pengasuh pondok pesantren tersebut.

Kerangka lain yang tidak bisa diakses adalah melakukan proses generalisasi pendidikan toleransi di luar lembaga pendidikan Islam (baca; pesantren). Di luar pesantren tidak memiliki role-model (Kyai) laiknya yang ada di pesantren. Oleh karena itu, diperlukan proses-proses pembaharuan untuk bisa menghadirkan pendidikan toleran berbasis pada nilai-nilai kepesantrenan ini sebagai basis utama sistem pendidikan nasional. Salah satu caranya adalah membingkai ulang desain pendidikan toleransi di luar, kemudian membawanya ke pengalaman-pengamalan yang basis nilainya ada di lembaga pesantren. Hal tersebut, dalam wujud implementasi, tentunya tidak sulit. Pasalnya, branding of full-day school dan building of Islamic Culture sudah menjadi primadona di kalangan masyarakat Indonesia, utamanya mereka yang berada di wilayah perkotaan.

\section{Penutup}

Betapapun rancang bangun identitas Islam di Indonesia tidak akan pernah lepas dari nilai-nilai toleransi dan kesadaran takdiri bahwa nusantara dibangun dari keragaman. Nusantara dibentuk dari perbedaan-perbedaan yang berkembang tanpa proses diminta. Oleh karena itulah, memotret Islam-Indonesia vis a vis dengan 
gerakan penyeragaman yang dilakukan oleh gerakan transnasional sebenarnya bukan perkara yang sulit. Indonesia memiliki identitas keislaman yang dipresentasikan dan dipreferensikan melalui dua organisasi yang lahir memberikan kontribusi terhadap berdirinya bangsa Indonesia; yakni Nahdlatul Ulama’ dan Muhammadiyah keduanya pun memiliki cara dan strategi tersendiri untuk mengkonstruk masyarakat Indoensia. Muhammadiyah bisa jadi melalui cara-cara dan jalan rasionalisme ilmiah, sedangkan NU melalui karakteristik yang dibangun di pondok pesantren.

Oleh sebab menjadikan pendidikan pesantren merupakan miniatur Indonesia yang beragam, memindahkan nilai-nilai keislaman pesantren yang toleran dan plural, juga merupakan sebuah keniscayaan. Hal yang dibutuhkan adalah melakukan konstruksi sosial, membingkai nilai, dan memantapkan regulasi serta komitmen bersama, untuk menciptakan lembaga pendidikan Islam yang toleran dan plural. Lebih-lebih, lembaga pendidikan di luar pondok pesantren memiliki kekuatan (internal/eksternal); apakah itu Sumber Daya Manusia ataupun Sumber Daya Alam, yang dapat mendukung dan menguatkan apapun yang sudah dicanangkan oleh lembaga pendidikan formal. In the end, apapun gagasan yang penulis tuangkan di atas, merupakan proses postulasi Islam-Indonesia yang sangat toleran dan berbeda dengan gerakan transnasional Islam, dalam mengahadapi masalah masyarakat, serta IslamIndonesia memiliki keunikan pendekatan untuk mereproduksi generasi muda yang toleran dan plural, melalui sekolah Islam ataupun pendidikan pesantren.

\section{Referensi}

Abdullah, Taufik (ed.), Ensiklopedi Tematis Dunia Islam volume 5 Asia Tenggara, Jakarta: PT. Ichtiar Baru van Hoeve, 2005.

Arikunto, Suharsimi, Metodologi Penelitian Kualitatif, Jakarta: Grafindo Persada, 1991.

Assegaf, Abdur Rahman, dkk, Pendidikan Islam di Indonesia, Yogyakarta: SUKA PRESS, 2007.

Attas (al), Naquib, Aim And Objectives Of Islamic Education, Mecca: King Abdul Aziz University, 1977. 
Azzumardi Azra, Pembaharuan Pendidikan Islam (tulisan dimuat di Harian Republika 21 April 2011).

Banks, James A. Multiethnic Education: Theory and Practice, London: Oxford University Press, 1994.

Dhofier, Zamakhsyari, Tradisi Pesantren: Studi tentang Pandangan Hidup Kyai, Jakarta: LP3ES, 1984.

Drajat, Zakiah, Ilmu Pendidikan Islam, Jakarta: Bina Aksara, 2008.

Fair, C. Cristine, Islamic Education in Pakistan, Report of United State Institute of Peace, 2006.

Fealy, Greg dan Anthony Bubalo, Jejak Kafilah, Bandung: Mizan, 2007.

Gulen, Fethullah, Love and Tolerance, New Jersey: Tughra Book, 2009.

Hackett, Rosalind I. J. "Anthropology of religion" dalam The Routledge Companion to the Study of Religion Edited by John R. Hinnells, London : Rutledge, 2005.

Hadi, Sutrisno, Metodologi Research, Yogyakarta: UGM press, 1993.

Hasbullah, Sejarah Pendidikan Islam di Indonesia, Jakarta: PT. Raja Grafindo Persada, 1999.

Hefner, Robert W, "Islamic School, Sosial Movement, and Democracy in Indonesia", dalam Robert W. Hefner edit, Making Modern islam Politic of Education in South Asia, USA: Hawai University Press, 2009.

Hilmy, Masdar dan Akh. Muzaki, Dinamika Baru Studi Islam, Surabaya : Arkola, 2005.

Hilmy, Masdar, "Akar-Akar Transnasional Hizbut Tahrir Indonesia” dalam Islamica, vol 61 september 2011.

Ihsan, Hamdani dan A. Fuad Ihsan, Filsafat Pendidikan Islam, Bandung: CV Pustaka Setia, 2007.

Jahroni, Jajang, The Political Economy of Knowlegde; Shari'a and Saudi Scholarship in Indonesia, Paper AICIS 2012.

Jalaluddin, Filsafat Pndidikan Islam, Jakarta: PT Raja Grafindo Persada, 1991.

Jalaluddin, Teologi Pendidikan (Jakarta: Rajawali Press, 2003), 115.

Kinball, Solonn T, Anthropology and education, New York : tp, 1956.

Maarif, Syafi'I, Islam dalam Bingkai keindonesiaan, Sebuah Refleksi Sejarah, Bandung: Mizan, 2009. 
Madjid, Nurcholish, Bilik-Bilik Pesantren: Sebuah Potret Perjalanan, Jakarta: Paramadina, 1997.

Majid, Abdul dan Dian Andayani, Pendidikan Karakter Persepektif Islam, Bandung: PT. Remaja Rosdakarya, 2012.

Marimba, Ahmad D., Pengantar Filsafat Pendidikan Islam, Bandung: PT. Al-Maarif. 1962.

Moleong, Lexy, Metode Penelitian Kualitatif, Jakarta: Remaja Rosdakarya, 2004.

Morita, Toyoko, Islamic, Education, and Human Rigth in Iran dalam buku Human Rigth in Asian School.

Mubarak, M. Zaki, Genealogi Islam Radikal di Indonesia Gerakan, Pemikiran dan Prospek Demokrasi, Jakarta: LP3ES, 2007.

Muhaimin, Ilmu Pendidikan Islam, Malang: UIN Press, 2003.

Muhajir, Noeng, Metode Penelitian Kualitatif, Yogyakarta: Rake Sarasin, 2000.

Mumtaz Ahmad, Madrasah Education in Pakistan and Bangladesh, Paper Of Radicalism and Security Of South Asia.

Nahlawi (al), Abd. Rahman, Prinsip-Prinsip dan Metode Pendidikan Islam, Jakarta: CV. Dipenogoro, 1992.

Nahlawi (al), Abdurrahman Prinsip-prinsip dan Metode Pendidikan Islam, Bandung: CV. Diponegoro, 1996.

Nawab Mohsin-ul-Mulk (ed.), Addresses and Speeches Relating to the Mubammadan Anqlo-Oriental College in Aligarh from its Foundation in 1875 to 1898 (Aligarh, Desember 1998), 31-32.

Rahman, Kholilur, "Konsep Pendidikan KH. Hasyim Muzadi”, Thesis--IAIN Sunan Ampel Surabaya, 2011.

Rahmat, M. Imdadur, Ideologi politik PKS, Jogjakarta: LkiS, 2008.

Ramayulis dan Samsul Nizar, Filsafat Pendidikan Islam Telaah Sistem Pendidikan dan Pemikiran Para Tokohnya, Jakarta: Kalam Mulia, 2010.

Ramayulis, Ilmu Pendidikan Islam, Jakarta: Kalam Mulia, 2011.

Sigit, Suhardi, Pengantar Metodologi Penelitian Sosial-Bisnis-Manajemen, Bandung: Lukman Offset, 1999. 
Suhartono, Suparlan, Filsafat Pendidikan, Jogjakarta: Ar-Ruzz, 2006.

Sukamadina, Nana Syaodih, Metode Penelitian Pendidikan, Bandung: Rosdakarya, 2007.

Sunyoto, Agus, Walisongo, Yogyakarta: Serambi, 2010.

Tilaar, HAR, Pendidikan dan Kekuasaan Manajemen Pendidikan Nasional dalam Pusaran Kekuasaan, Jakarta: Reineka Cipta, 2003.

Wahid, Abdurrahman (ed), Ilusi Negara Islam ekspansi gerakan Islam Transnasional di Indonesia, Jakarta : Wahid Institute, 2009.

Weismann, Mikael, The Missing Link - bridging between social theory and conflict resolution, University off Gothenburg, 2008.

\section{Internet}

http://www.salafyoon.net/manhaj/hizbut-tahrir.html http://www.suara-Islam.com http:/ / hizbut-tahrir.or.id/2007/07/19/bahaya-ideologi-transnasional/ http://hizbut-tahrir.or.id/tentang-kami/ 